\title{
CONGENITAL PSEUDOARTHOSIS OF TIBIA: A CASE REPORT
}

Madhukar K. T11, Sateesh G. S², Ankit Prasad ${ }^{3}$

\section{HOW TO CITE THIS ARTICLE:}

Madhukar K. T, Sateesh G. S, Ankit Prasad. "Congenital Pseudoarthosis of Tibia: A Case Report". Journal of Evolution of Medical and Dental Sciences 2014; Vol. 3, Issue 53, October 16; Page: 12371-12374,

DOI: $10.14260 /$ jemds/2014/3635

ABSTRACT: Congenital pseudoarthosis of tibia is a rare condition. The incidence ranges from $1: 140000$ to $1: 250000.50 \%$ to $90 \%$ of the cases show association with neurofibromatosis stigmata including skin and osseous lesions. It is usually associated with a dysplastic segment of bone, which undergoes fracture after a trivial trauma or spontaneously. This fracture then goes into non-healing leading to pseudoarthosis. It is a difficult condition to treat and may be associated with complications. Treatment is mainly surgical, aiming at fracture union and maintaining limb length. This is a case report of a 6 year old boy, who presented with progressive deformity of right leg. He was diagnosed with congenital pseudoarthosis and treated accordingly with multiple osteotomies, bone grafting, intramedullary nailing and stabilization with ilizarao external fixator followed by cast immobilization. On follow up deformity was corrected and union was achieved.

KEYWORDS: Congenital pseudoarthosis tibia, neurofibromatosis, multiple osteotomies.

BACKGROUND: Congenital pseudoarthosis of tibia is a rare condition. It is considered as one of the most challenging problems in paediatric orthoapedics. Very commonly it is found to be associated with Neurofibromatosis type 1. Histopathologically it is found to be associated with fibrous hamartoma formation. Bowing and tibial nonunion may lead to limb shortening. Treatment of CPT has always been challenging with surgical treatment being the main form of treatment. Historically various forms of surgical treatment has been tried including amputation, use of intramedullary nail with or without supplementary use of bone grafting, BMP 7, external fixator, but the debate on more successful form of modality is still inconclusive.

CASE REPORT: A 6yrs old male patient presented with the chief complaint of deformity of the right lower limb since birth. There was no history of involvement of any other body part. There was no history of similar complaints in the family members or any form of surgical treatment received for the same. There was no evidence of any swelling or spots over the skin. The deformity was progressive in nature and the child was having difficulty in walking because of the same. On local examination, anterolateral bowing of the tibia was visible with shortening of the limb. It was found to be painful on deep palpation, abnormal mobility was present.

The diagnosis was made after taking the plain radiographs of the involved leg. The lesion was classified under Boyd type 3 CPT. Patient was treated surgically with multiple level osteotomies and substituted with cancellous bone grafts obtained from the iliac crest. The osteotomised tibia was stabilized with an intramedullary elastic nail supplemented with ilizarao ring external fixator was applied. Immediate post-operative period was uneventful. The nail was kept in situ for three months till there were signs of union on follow up x-rays. Post operatively there was one instance of pin site infection and was managed conservatively with regular dressings and antibiotics. 


\section{CASE REPORT}

Later at the end of 9 months fixator was removed and the limb was immobilized in a long leg POP cast. The follow up x-rays taken at 12 months and 18 months showed signs of union and correction of deformity.

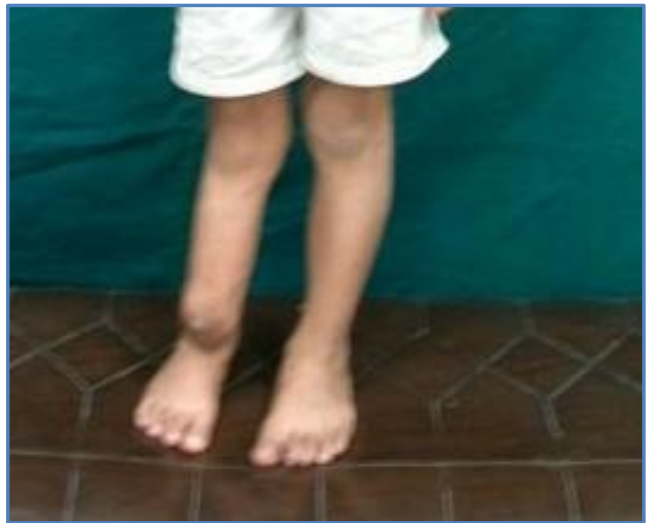

Clinical photograph showing anterolateral bowing of the leg

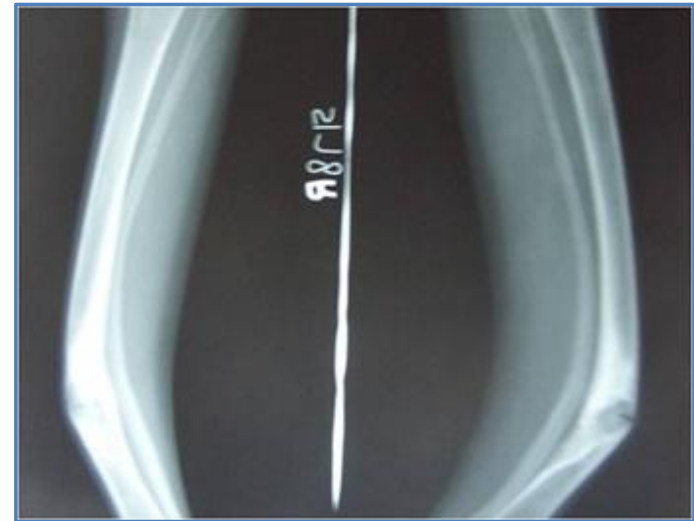

$\mathrm{X}$ ray demonstrating deformity and pseudarthrosis of tibia

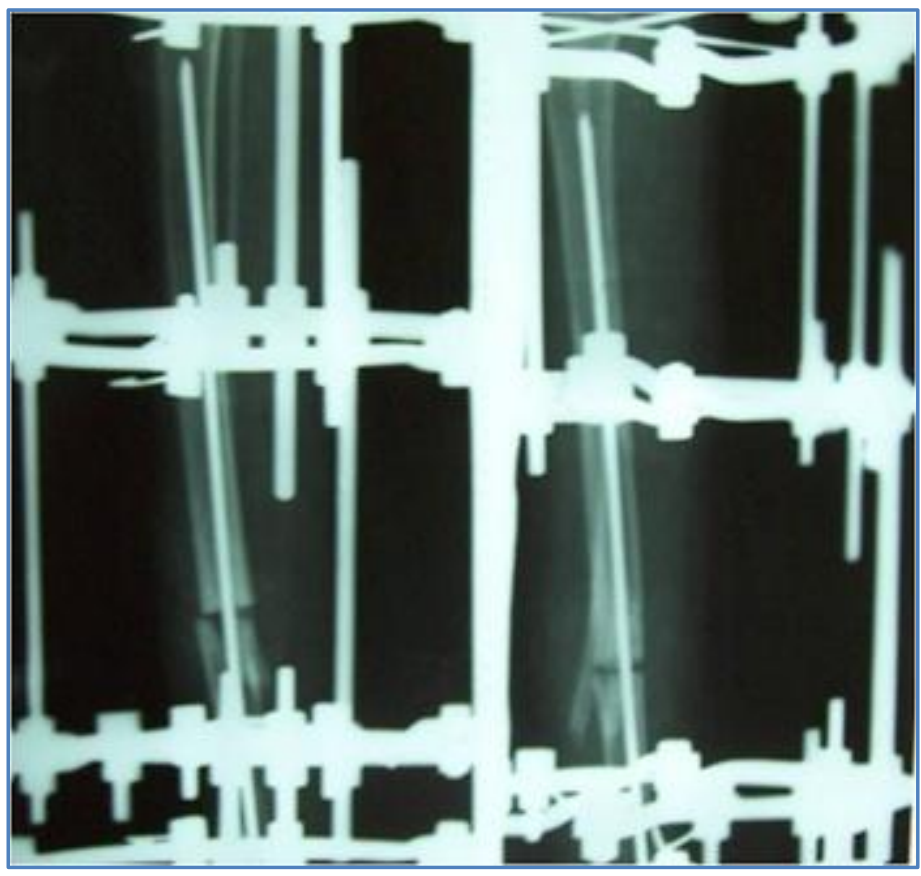

Multiple osteotomies, intramedullary stabilization and ring fixator applied for correction of deformity and to achieve union 


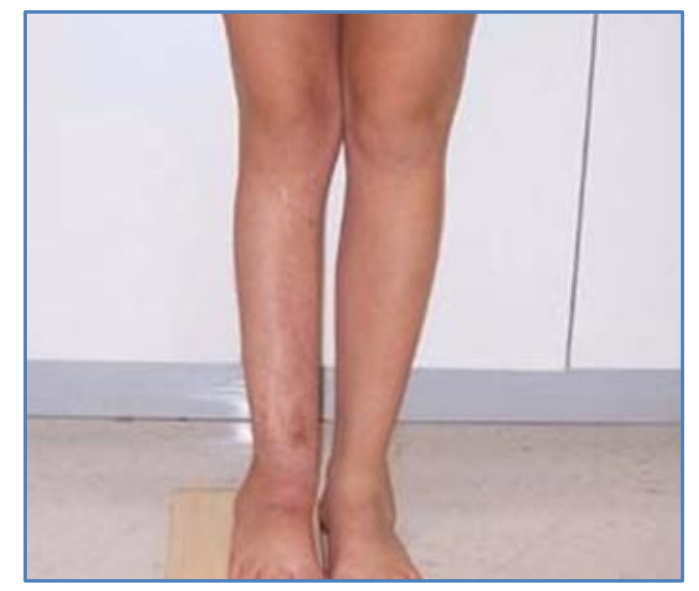

Deformity corrected and union achieved

DISCUSSION: Congenital pseudoarthosis of tibia is rare condition with incidence ranging from 1:125000 to $1: 140000^{1}$. It is associated with stigmata's of neurofibromatosis in $50-90 \%$ cases. $^{2}$ The disease is usually detected by the age of two years, but it may take up to 12 years to be detected. ${ }^{3}$

Fibrous hamartoma is the key pathology behind congenital pseudoarthosis. This is more commonly of the osteolytic type. Failures in union in these patients are because of the recurrence of the fibromatosis. There are various classifications given for this condition - Boyd's, Crawford's, EIRosasy-Paley-Herzenberg's classification. CPT has been classified into 6 different types according to Boyd'sclassification. ${ }^{4}$

Type 1 is described as anterior bowing with a defect in the tibia. Type 2 is dysplastic lesion with anterolateral bowing and hourglass constriction. This is often associated with neurofibromatosis. Type 3 is a cystic deformity with bone cysts at the junction of the middle and lower third of tibia. Type 4 is described as originating in a sclerotic segment of the tibia without any narrowing or fractures. Type 5 is dysplastic fibula and Type 6 is an intraosseous neurofibroma or schwannoma with or without pseudoarthosis. Our case was classified as type3. Once a fracture occurs, there is minimal chances of healing spontaneously, making its natural history unfavorable. ${ }^{4}$

Treatment aims to obtain a long term bony union of tibia and fibula, to prevent limb-length discrepancy, to avoid mechanical axis deviation, soft tissues lesions, nearby joint stiffness, and pathological fractures. ${ }^{5} \mathrm{~A}$ multitude of treatment protocols have been described and have varying degrees of success. ${ }^{6}$ Most of these treatments focused on stimulating the healing process by using different bone grafting techniques. The graft materials most commonly used include osteoperiosteal graft, massive on lay graft, autogenously iliac crest bone graft (ICBG), and vascularized bone graft.7,8

The fixation methods also varied widely between cortical fixation using bone or metal plates, intramedullary (IM) rods of different types, external skeletal fixation, and lastly external skeletal fixation augmented by IM rod. ${ }^{9,10}$ However, none of invasive or noninvasive method has yet proven its superiority. 


\section{REFERENCES:}

1. Ollini G, Dungl P, Fixsen J, Grill F, Ippolito E, et al. Congenital pseudoarthrosis of the tibia: History, etiology, classification, and epidemiologic data. J Pediatr Orthop B. 2000; 9: 11-5.

2. Campbell. Text book of orthopedics vol. 12.

3. AD Delgado-Martinez, E Crodrigez-Merchan, B Olsen. Congenital pseudarthrosis of the tibia. Int Orthop, 20 (1996) 192.

4. AH, Staatz G, Hermanns B, Gunther RW, Weber M. Congenital pseudarthrosis of the tibia in pediatric patients: MR imaging. AJR Am J Roentgenol. 2001;177:1025-9

5. CE., 2nd congenital pseudoarthrosis of the tibia: Results of technical variations in the charnleywilliams procedure. J Bone Joint Surg Am.2002; 84-A: 1799-810.

6. Joseph B, Somarajuvv, Shetty SK. Management of congenital pseudoarthrosis of the tibia in children under 3 years of age: effect of early surgery on union of the pseudoarthrosis and growth of the limb. J Pediatr Orthop 2003; 23(6):740-746.

7. Umber JS, Moss SW, Coleman SS. Surgical treatment of congenital pseudoarthrosis of the tibia. Clin Orthop 1982; 166: 28-33.

8. Weiland AI, Weiss AP, Moore JR, Tolo VT. Vascularized fibular grafts in the treatment of congenital pseudoarthrosis of the tibia. J Bone Joint Surg Am 1990; 72: 654-662.

9. Dobbs MB, Rich MM, Gordon JE, Szymanski DA, Schoenecker PL. Use of an intramedullary rod for the treatment of congenital pseudoarthrosis of the tibia. A long-term follow-up study. J Bone Joint Surg Am 2004; 86(6):1186-1197.

10. Johnston CE II. Congenital pseudoarthrosis of the tibia: results of technical variations in the Charnley-Williams procedure. J Bone Joint Surg Am 2002; 84 (10): 1799-1810.

11.

\section{AUTHORS:}

1. Madhukar K. T.

2. Sateesh G. S.

3. Ankit Prasad

\section{PARTICULARS OF CONTRIBUTORS:}

1. Associate Professor, Department of Orthopaedics, Adichunchanagiri Institute of Medical Sciences, Mandya.

2. Assistant Professor, Department of Orthopaedics, Adichunchanagiri Institute of Medical Sciences, Mandya.

3. Resident, Department of Orthopaedics, Adichunchanagiri Institute of Medical Sciences, Mandya.

\section{NAME ADDRESS EMAIL ID OF THE CORRESPONDING AUTHOR: \\ Dr. Madhukar K. T, \#176 Sampada, Siddivinayaka Block, Teachers Layout, Mysore-570029. \\ Email: drmadhukarkt@gmail.com}

Date of Submission: 20/09/2014.

Date of Peer Review: 22/09/2014.

Date of Acceptance: 09/10/2014.

Date of Publishing: 16/10/2014. 